revista do ieb n 45 p. 123-140 set 2007

\title{
Etnicidade, ideologia e herança cultural através da música para koto no Brasil
}

Alice Lumi Satomi*

Resumo

Trata-se de uma sinopse do estudo de caso iniciado em 1996, enfocando a Associação Okinawa do Brasil, o Grupo Miwa e a Associação Brasileira de Música Clássica Japonesa, na cidade de São Paulo. A pesquisa anotou a organização, estrutura, atitudes e conceitos dessas instituições, observando o ensino, o aprendizado e a exibição artística. Através das escolas de koto, pretendeu-se verificar o papel sócio-cultural da música tradicional em contexto transterritorial. Trata-se, pois, de um tema transversal para se realçarem alguns dos reflexos relevantes do comportamento e da história da imigração japonesa no Brasil, cujo centenário se completa em 18 de junho de 2008. A temática, envolvendo repertório de imigrantes, busca contribuir para os estudos de antropologia urbana em discussões sobre minorias étnicas, especificamente a comunidade nikkei, no caso, nipobrasileira.

\section{Palavras-chave}

minorias urbanas, comportamento nikkei, escolas de koto, Grupo Miwa, Associção Brasileira de Música Japonesa.

*Professora do Depto. de Educação Musical e do Programa de Pós-Graduação em Música (etnomusicologia) do Centro de Cências Humanas, Letras e Artes da Universidade Federal da Paraíba. 
revista do ieb n 45 p. 123-140 set 2007

\title{
Ethnicity, ideology and cultural inheritance through koto music in Brazil
}

Alice Lumi Satomi

\begin{abstract}
This article summarizes the case study initiated in 1996, encompassing Okinawa Brazilian Association, Miwa Group, and the Japanese Classical Music Brazilian Association, located in the city of São Paulo. The research dealt with the institutions' structural organization, attitudes and concepts regarding teaching, learning and performance. Through the koto schools, the social cultural role of traditional music was examined in its international context. In order to highlight some of the relevant consequences of the behavior and history of the Japanese immigration to Brazil, which centenary will take place in June $18^{\text {th }} 2008$, the research went beyond subject barriers, focusing in an transversal approach. The article, through the research of immigrant repertoires, attempts to contribute for the urban anthropology studies by discussing ethnic minorities, specifically, Nikkei community.
\end{abstract}

\section{Keywords}

urban minorities, Nikkei behavior, koto schools, Miwa Group, Japanese Classical Music Brazilian Association. 


\section{Considerações iniciais}

0 presente artigo é uma sinopse da tese defendida, em 2004 - na Universidade Federal da Bahia, sob a orientação do professor Luis César Magalhães -, que examinou a dinâmica de continuidade da "sôkyoku1 [música para koto]", procurando atualizar um recorte do artigo seminal de Dale Olsen (1982) ${ }^{2}$. 0 estudo de caso se concentrou na Grande São Paulo ${ }^{3}$, centro das manifestações musicais da comunidade nipo-brasileira, doravante denominada nikkei. Apesar do karaokê $\hat{e}^{4}$ constituir a atividade musical predominante do nikkei brasileiro, a música clássica japonesa é a mais representativa dos eventos restritos ou não à comunidade local. Até mesmo nas comemorações especiais de aniversários da imigração japonesa dos países vizinhos - tais como Peru, Bolívia, Argentina, Chile e Paraguai -, é solicitada a presença de intérpretes da música "koten [clássica]" residentes no Brasil, geralmente um trio sankyoku - integrado pelo aerofone shakuhachi e os cordofones koto e shamisen.

"Dragão deitado na areia conversa com as ondas"5 é a imagem poética do koto, cujas cordas são apoiadas em cavaletes móveis e tocadas com plectros. A denominação de suas partes remonta à simbologia da família das cítaras pranchiformes chi-

1 Os termos estrangeiros que estão em itálico apresentam uma tradução ou explicação em algum momento do corpo do texto ou em nota de rodapé. Quando o nome próprio estiver em itálico, trata-se de pseudônimo artístico.

2 OLSEN, Dale. Japanese music in Brazil. Journal of the Society for Asian Music, Austin, v. 14, n. 1, p. 111-31, 1982.

3 Na Grande São Paulo vivem em torno de 425 mil nikkei, ou seja 26,55\% de toda a comunidade no Brasil, somando os issei, seus descendentes até a quinta geração e os 20\% de dekasegi - trabalhadores temporários no Japão. Como inexiste o plural no idioma japonês, os termos como nikkei e issei são mantidos sem concordância.

4 A perspectiva histórica e sociológica sobre a música vocal urbana, desde os concursos de calouros Nodo Jiman até os campeonatos atuais de karaokê, já foi suficientemente abordada por HOSOKAWA, Shûhei. História da música entre os nikkei no Brasil: enfocando as melodias japonesas. In: ENCONTRO NACIONAL DE PROFESSORES UNIVERSITÁRIOS DE LÍNGUA, LITERATURA E CULTURA JAPONESA, 4., 1993, São Paulo. Anais... São Paulo: Centro de Estudos Japoneses da USP, 1993. p. 125-48; HOSOKAWA, Shûhei. 0 feitiço do karaokê. D. O. Leitura, São Paulo, v. 11, n. 133, p. 2-3, 1993.

5 Imagem lembrada por Tranchefort: "un dragon couché sur une plage et conversant avec des vagues". TRANCHEFORT, François-René. Instruments de musique dans le monde. Paris: Éditions du Seuil, 1980. v. 1, p. 180. 
nesas ch'in e cheng. Segundo Yu-ch'in Sun (p. 3) ${ }^{6}$ e Tsun-yen Lui $(\mathrm{p} .180)^{7}$ : o calendário lunar é representado pelas treze cordas; a concepção binária do yin/yang ou in/yo se apresenta no formato - o tampo superior abaulado representa o céu yang e o fundo achatado, a terra yin - e nas fontes míticas de vitalidade e fertilidade do dragão e da fênix. Por exemplo, na extremidade onde se toca estão representadas a cabeça, crista, língua, pés e reservatório do dragão e, na outra extremidade, a crista, cauda, pés e reservatório da fênix. A afinação pentatônica também estaria relacionada a outra concepção taoísta, a dos cinco elementos - metal, água, terra, madeira e fogo - ou às relações humanas ou "as cinco afinidades" referidas por Confúcio: governador e ministro, marido e mulher, pai e filho, irmão mais velho e irmão mais novo, amigo e amigo. A harmonia céu/terra/homem está presente também nos preceitos budistas. Conseqüentemente, podemos conferir a síntese dos fundamentos budistas, taoístas e confucionistas num único instrumento.

A delimitação temática se deu a partir de motivações pessoais como a tendência pela organologia e a necessidade de continuidade e amadurecimento na interpretação das relações sociais e culturais do assunto referente às "minorias étnicas", iniciada com a pesquisa sobre a música de Okinawa em São Paulo $^{8}$. Devido à supressão da imigração, na década de setenta, e à inversão do fluxo migratório na década subseqüente, a tendência é a diminuição do issei. Desde a pesquisa anterior fui constatando a idade avançada - e até mesmo o falecimento - dos principais professores da música vernacular, apontando sintomas de esmorecimento das escolas de música koten.

Antes de prosseguir, alguns esclarecimentos sobre a música para koto se fazem necessários. No Japão atual sobrevivem, basicamente, duas "ryû [corrente]" de sôkyoku: a Ikuta e a Yamada. A primeira, fundada por kengyô ${ }^{9}$ Ikuta (1656-1715) na região de Quioto, utiliza o plectro de ponta reta que permite uma técnica de execução semelhante à do alaúde, exigindo que o executante

6 WALKER, J. L. No need to listen!: a conversation between Sun Yu-Ch'in and J. L. Walker. Parabola, Toronto, v. 23, n. 2, p. 1-6, 1998.

7 LUI, Tsun-yuen. A short guide to ch'in. Selected reports in ethnomusicology, v. 16, n. 1, p. 179-203, 1982.

8 Cf. SATOMI, Alice Lumi. As gotas de chuva do telhado: música de Ryûkyû em São Paulo. 1998. Dissertação (Mestrado em etnomusicologia) - Universidade Federal da Bahia, Salvador, 1998.

9 Kengyô é a titulação máxima da corporação profissionalizante chamada todô shokuyashiki, sistema em que os deficientes visuais eram habilitados para a música, teatro e massagem. 


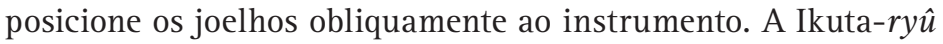
acrescentou as "jiuta [canções regionais]", de Quioto e Osaka, ao repertório da Yatsuhashi-ryû; estabeleceu o trio sankyoku $u^{10}$; criou a forma interlúdica tegotomono; e desenvolveu a linguagem polifônica kaete, acoplando uma segunda linha melódica. A segunda corrente - fundada por kengyô Yamada, que viveu entre 1757 e 1817 na região de Quioto e Osaka - retomou a música de caráter narrativo e o plectro de ponta arredondada, bem como ampliou a extensão do koto para o agudo, criando a afinação kumoijôshi.

A pesquisa de campo lidou com três grupos principais de sôkyoku: a Associação Okinawa do Brasil (AOB), que possui duas filiais das escolas de Ryûkyu $\hat{u}^{11}$ atreladas a si; o Grupo Miwa, simpatizante da corrente Ikuta-rŷu; e a Associação Brasileira de Música Clássica Japonesa (ABMCJ), que envolve duas intérpretes da Yamada-rŷu e duas subescolas da Ikuta-ryû, Miyagi e Seiha. Nas duas primeiras associações prevalecem atitudes coletivistas, peculiares ao imigrante rural do pré-guerra, e nos grupos da ABMCJ predomina a mentalidade moderna e urbana do imigrante pós-guerra. Dessa forma, o título do artigo se justifica pela apresentação dos pressupostos comportamentais levantados no início da pesquisa. A etnicidade seria mais pronunciada na $\mathrm{AOB}$, a herança cultural, no Grupo Miwa, e a ideologia na ABMCJ.

Os três grupos musicais foram enfocados prosseguindo na linha de abordagem "surgimento, manutenção e adaptação", da dissertação citada anteriormente, aproximando-se da proposta "construção histórica, manutenção social e criação individual da música”, de Timothy Rice (p. 473) ${ }^{12}$. Ao invés da terminologia "transplante cultural", preferi adotar o termo "transterritorialização" ou aplicar o conceito de "alternativização"13, ou seja, um repertório oficial no país natal, que passa a ser alternativo na terra de acolhimento.

10 Inicialmente era integrado por koto, shamisen e kokŷu - este é um cordofone similar ao shamisen, tocado com arco, que, mais tarde, foi substituído pelo shakuhachi.

11 Ryûkyû é o arquipélago ao sul do Japão, que engloba a prefeitura de Okinawa e parte de Kagoshima. Embora seja uma designação "ética [visão de fora]" advinda de "léquios", termo criado por Marco Pólo para os habitantes daquela região, é hoje uma nomenclatura "êmica [visão de dentro]", pois enfatiza um passado independente e soberano.

12 Cf. Rice, Timothy. Toward the remodeling of ethnomusicology. Ethnomusicology, Austin, v. 31, n. 4, p. 469-88, 1987.

13 Cf. Satomi, Alice Lumi. Dragão confabulando: etnicidade, ideologia e herança cultural através da música para koto no Brasil. 2004. Tese (Doutorado em etnomusicologia) - Universidade Federal da Bahia, Salvador, 2004. p. 5. 
A Associação Okinawa do Brasil, sediada no bairro da Liberdade, é a matriz de quarenta e duas subsedes espalhadas pelo país, dezesseis das quais concentradas somente na cidade de São Paulo, o que indica a sua capacidade coesiva. Embora os provenientes de Okinawa sejam os mais numerosos na terra adotiva, predomina o comportamento de minoria da terra mãe. Para ilustrar tal conduta costumo considerar adequada a afirmação da sansei (neta de issei) da família Shimabukuro que, após se identificar com o nordestino brasileiro, pela discriminação e pela condição político-econômica subalterna, arrisca um estereótipo idiossincrático: "Somos o pessoal da música mais cadenciada, da pele mais escura, dos olhos mais redondos, da alma mais tropical e do bolso mais pobre do Japão" (p. 66) ${ }^{14}$.

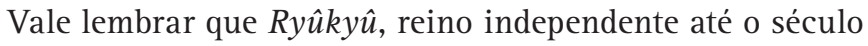
XIV, foi dominado economicamente pela China e, politicamente, pelo Japão e Estados Unidos. Reportando-se à última subordinação, Humberto Kinjô, jornalista, neto de um passageiro do " $\mathrm{Ka}$ sato Maru" (nome do primeiro navio da imigração), indigna-se:

No período da ocupação americana nós tínhamos que pedir permissão a Washington para visitar nossos parentes. Imagine você ter que pedir licença a um estranho para entrar em sua própria casa! ${ }^{15}$

Chinkun Chibana, presidente de um dos grêmios musicais de koten, reforça o senso comum antiamericano, comparando a música midiática dos dois países: "Prefiro ouvir música sertaneja, que eu não entendo nada, do que a enka, contaminada de termos em inglês."16

0 esquema 1 mostra as possibilidades múltiplas de etnicidade - entendida aqui como "sentimento de pertença [...] e estabelecimento da categorização entre “nós' e ‘eles”"17. A ordem

14 HARAZIM, Dorrit. Vidas em suspense. Veja, São Paulo, v. 27, n. 24, p. 62-66, 1998.

15 Em conversa informal, anotada na página 55 da caderneta de campo, em 13.08.1996, na residência da mãe da pesquisadora, em Parada de Taipas, bairro extremo noroeste da cidade.

16 Entrevista gravada em fita cassete áudio n. 17, lado A, em 14.01.1997, na residência do professor Chibana, no bairro de Vila Carrão, zona oeste.

17 SEYFERTH, Giralda. Etnicidade. In: DICIONÁRIO de Ciências Sociais. Rio de Janeiro: Fundação Getúlio Vargas, 1987. p. 436. 


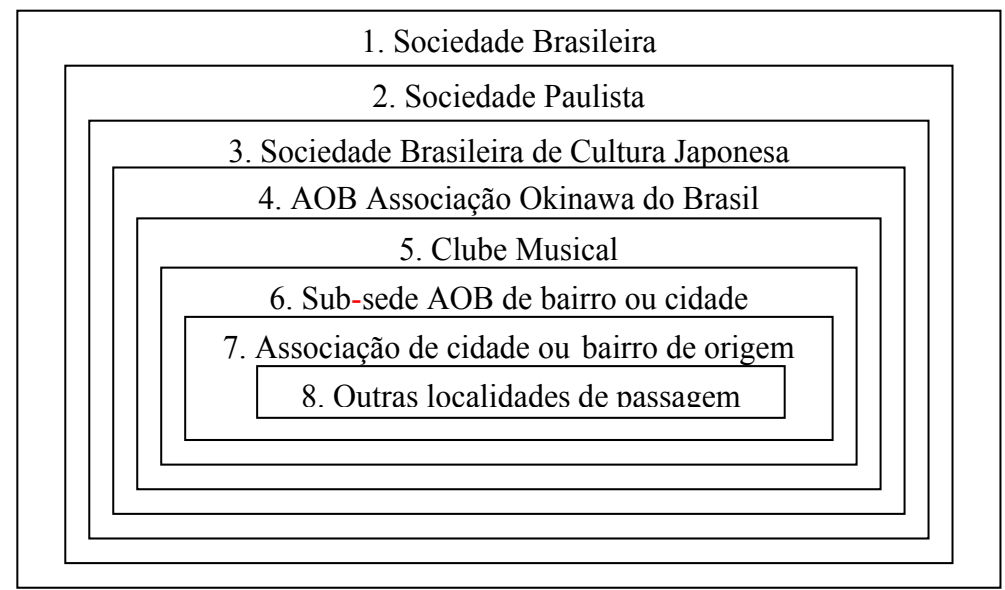

Esquema 1. Possibilidades associativas dos okinawanos

obedece à seqüência apresentada nos cartões de visitas ou nas hierarquias dos discursos na abertura dos eventos ${ }^{18}$. 0 professor Chibana, por exemplo, acumula funções nas camadas 4 a 7 . Além de participar da diretoria da AOB, do clube musical, ele participa também da diretoria da subsede da Vila Carrão e da aldeia Yomitan-son, onde nasceu e cresceu. Na festa dos 95 anos da imigração, a AOB homenageou a liderança musical entre os imigrantes, num patamar acima dos políticos descendentes de Okinawa, pertencentes às camadas 1 e 2 da sociedade majoritária. Essas atribuições atestam o papel da música, um verdadeiro estandarte da identidade e soberania cultural, conforme a assertiva de Ernesto Arashiro ${ }^{19}$ :

Ser uchinanchû [okinawano] é não esquecer jamais a história de lutas e sofrimentos deste povo. É dar continuidade a essa luta como quem luta pela sobrevivência [...] sem jamais esquecer as origens. É saber apreciar suas músicas, danças e a culinária ${ }^{20}$.

0 evento mais aglutinador da AOB, o Festival Folclórico do mês de julho, exibe oito grupos de música vernacular - sem

18 As camadas internas não se esgotam na oitava camada e podem desembocar em troncos familiares ou até nas díades sociais levantadas por Confúcio, ou até mesmo em torcidas de times de futebol.

19 Nisei paranaense, diretor de empresa alemã em Manaus, que concedeu o depoimento ao jornalista Marcelo Chinen.

20 Chinen, Marcelo. Ernesto Arashiro, um uchinanchu no coração da Amazônia. Utiná Press, São Paulo, ano 5, v. 50, p. 3, 2002. 
contar as onze academias de dança, classificáveis por geração, faixa etária ou gênero: quatro filiais de música koten, em que a maioria é issei da terceira idade, mulheres tocam kutû (koto) e os homens o alaúde sanshin; dois clubes de minyô (música folclórica), cuja predominância é nisei na faixa ativa de trabalho; e duas escolas do tambor taiko, integradas por sansei a gosei (tataranetos) na faixa escolar. Para as apresentações de koten, juntando-se a ala masculina e a feminina, há, praticamente, dois grupos: o "Hozonkai [Preservação]" e "Koyôkai [Difusão]". Em algumas ocasiões especiais, como a abertura do Festival mencionado, por exemplo, os principais líderes e veteranos disponíveis desses dois grupos tocam todos reunidos (Fig. 1).

No período pré-guerra, a prática da música clássica de Ryûkyû era informal devido às dificuldades da vida rural e à intensa mobilidade territorial dos okinawanos. A Segunda Guerra provocou uma maior fixação na zona urbana, a retomada do fluxo de imigrantes e a vinda de especialistas de koten, constituindo a causa principal da formalização das escolas que, por sua vez, é fruto da coesão dos okinawanos pré-guerra e pós-guerra.

Em Okinawa, o grande número de órfãos de guerra, o domínio americano e a omissão japonesa estimulavam a emigração. No Brasil, vigorava uma situação opressiva de duplo patrulhamento: o da ditadura Vargas - que proibia a aglutinação de imigrantes dos países do eixo; e a dos próprios compatriotas fanáticos da facção dos "kachigumi [irredentistas da Shindô Renmei]" - que impedia de certa forma a reunião dos "makegumi [esclarecidos sobre a derrota do Japão na Segunda Guerra]”. Os dissabores sociais em dimensões redobradas adiaram a tendência à formalização das agremiações de koten, mas terminaram por fortalecêla. 0 grupo da Preservação foi fundado em 1953, pelo imigrante pré-guerra Binsuke Shinzato e a Associação Nomura do Brasil, que contém o grupo da Difusão, em 1955, por Kishin Nakandakari.

Na especificidade das filiais de koto, o grupo da Preservação (PKB) aglutina associadas da zona leste de São Paulo, onde fica a maior subsede da AOB, no bairro de Vila Carrão. Como razão social, a PKB funciona desde 1963, mas foi reconhecida pela matriz de Okinawa em 1970. Hoje, o grupo ativo conta com vinte e duas integrantes orientadas pelas professoras Toyo Oshiro, Harue Yamada, Chibana Chieko e Yoshiko Miyazato. 0 grupo da Difusão (DKB) contém associadas em Campinas e na região do $\mathrm{ABC}$, mas o maior número se encontra no bairro da Casa Verde, zona norte. Desde 1975, o grupo DKB habilitou seis mestras e vinte professoras. As principais são Kayoko Shimabukuro, de Santo André, e Take Takara, da Casa Verde, ambas imigrantes pré-guerra. Elas foram as decanas homenageadas na comemoração dos 95 anos da imigração, contando, na época, 92 anos de idade. 
Os fatores da sobrevivência da música okinawana no Brasil são muito semelhantes à dinâmica observada por Anderson Sutton, no Havaí (p. 75-80) ${ }^{21}$. 0 processo de continuidade é alicerçado na disponibilidade de instrumentos, partituras e gravações; no contato permanente com as respectivas matrizes em Okinawa; na prática pelas novas gerações; no universo hierárquico dos concursos, performances e da aprendizagem; e, sobretudo no bairrismo, rivalidades entre escolas e a superioridade dos "naichi [demais japoneses]", que provocam o grande objetivo da coesão. "Além de amenizar o coração e a saudade, o significado principal da música é a união entre os associados”, simplifica a professora Chieko Chibana ${ }^{22}$.

\section{A herança familiar do Grupo Miwa}

O segundo grupo em que prevalece a conduta coletivista é o fundado por Miwa Miyoshi (1902-1994), proveniente de Hiroshima, em 1931. A maioria dos primeiros integrantes do Grupo de Estudos da Música e Dança Japonesa veio no mesmo navio do casal Miyoshi. 0 sr. Yoshimi Miyoshi ${ }^{23}$ (1901-1968) foi o introdutor da escola de shakuhachi Tozan-ryû e a sra. Miwa, entusiasta do nagauta ${ }^{24}$, a pioneira da Ikuta-ryû. 0 grupo estreou o recital "Noite da Música e Dança Japonesa”, em novembro de 1939, no Clube Lira de São Paulo, cujo título em japonês perdurou por cinqüenta anos, enquanto Miwa Miyoshi pôde tocar shamisen, koto, kokyû, ko-tsuzumi ${ }^{25}$ ou, pelo menos, cantar. Ela chegou a orientar 70 alunos (55 issei e 15 nisei), dos quais 26 de shamisen, 29 de koto e 15 tocando ambos os instrumentos.

0 percurso do grupo acompanha a trajetória da imigração japonesa. 0 casal aportou em terras brasileiras na década de

21 SUTTON, Anderson. Okinawan music overseas: a Hawaiian home. Journal of the Society for Asian Music, Austin, v. 15, n. 1, p. 54-80, 1983.

22 Em conversa informal, anotada na caderneta de campo, p. 43, em 16.02.2001, na residência da professora, no bairro de Santa Clara, subúrbio a leste da cidade de São Paulo.

23 Em 1959, ele recebeu o título de Okuden, um dos seis níveis para o ensino das artes tradicionais.

24 Literalmente "canção longa" ou "canção de amor". Trata-se de um gênero de música acompanhado de shamisen, utilizado no teatro Kabuki.

25 Este último, um membranofone de pele dupla, em forma de ampulheta, utilizado no teatro Noh. 
trinta, período de maior entrada de japoneses no Brasil. Quando o casal se transferiu para São Paulo, o consulado estava recéminstalado na capital. 0 caráter beneficente e o suporte institucional acompanham as vicissitudes e conquistas da comunidade. Enquanto houve apoio dos padres franciscanos, a comunidade vivia os dissabores da dupla vigília, a do Estado Novo e a da Shindo Renmei. A partir de 1954, fase de "recuperação da autoconfiança" (p. 398) ${ }^{26}$, começou a construção da sede da Sociedade Brasileira de Cultura Japonesa (SBCJ) e a consolidação das entidades beneficentes mantidas por ela.

Hoje, o casal Saito - Shigeo Shinzan e Miriam Sumie -, sucessor dos Miyoshi, apresenta-se anualmente em asilos e hospitais mantidos pela SBCJ, em Santos, Guarulhos e Campos do Jordão, prosseguindo a ação social iniciada pelo casal precursor. Fora do âmbito da comunidade, costumam apresentar-se em projetos da JICA, na favela do bairro Morumbi e para o Hospital do Câncer, de São Paulo, e, eventualmente, se apresentam em Londrina, Goiânia, Recife e João Pessoa. No Morumbi, Recife, Goiânia e Parque da Aclimação - bairro central de São Paulo onde ocorreu o I Encontro da Diversidade Cultural -, apresentaram-se ao ar livre ${ }^{27}$ para um público popular. E esse é o grande diferencial do Grupo Miwa ao admitir que o público-alvo não se restringe ao nikkei que pensa estar morando num pequeno Japão dentro do Brasil. Como prova disso, ao invés de buscar uma titulação na terra ancestral, a professora Miriam Saito ${ }^{28}$ preferiu buscar uma legitimização na própria terra natal. Em 2003, após submeter-se a provas de teoria e solfejo, sem nenhuma conexão com a linguagem musical japonesa, ela conseguiu a primeira carteira profissional em koto da Ordem dos Músicos do Brasil.

Desde os primórdios do Grupo de Estudos de Música e Dança Japonesa, já se manifestava uma maior liberdade para in-

26 YAMASHIRO, José; NAKASUMI, Tetsuo. Período do pós-guerra. In: UMA EPOPÉIA moderna: 80 anos da imigração japonesa no Brasil. São Paulo: Hucitec, SBCJ, 1992. cap. 5, p. 381-416.

270 grupo Miwa parece ser o único a aceitar essas propostas ao ar livre, talvez até confiando no poder do dragão (espírito das águas e das tormentas) e da fênix (pássaro de fogo) atribuído ao koto. Segundo Miriam Saito, o instrumento, trazido pela sua mãe Miwa Miyoshi, já sobreviveu a uma inundação no porão do navio e a um incêndio.

28 Nascida em 1938, começou a aprender dança antes do shamisen, aos seis anos de idade, e koto, aos oito anos, sempre com sua mãe. Mais tarde casouse com Shigeo Saito, atual presidente da Shinzan-kai, ala de shakuhachi que atua sempre com o grupo Miwa. Em 1984, passou a ser assistente da mãe, assumindo a liderança em 1990. 
corporar e adaptar-se ao novo ambiente, através de uma conduta musical influenciada pela variedade e improvisação. A professora Miyoshi tinha o hábito de arranjar as peças para facilitar o aprendizado das alunas. Seguindo a liberdade da mãe de criar adaptações de acordo com o recurso instrumental e humano, a professora Saito transpõe as peças para acomodá-las à extensão vocal, reduz partituras e elabora arranjos conforme encomendas.

A apresentação relevante para o grupo é a abertura da cerimônia budista na homenagem póstuma aos imigrantes que acontece no aniversário da imigração, em 18 de junho (Fig. 2). A abertura inclui apresentações simultâneas de ikebana - arte do arranjo floral -, cerimonial de chá e sôkyoku. Os treinamentos do Miwa-kai acontecem, principalmente, na residência do casal sucessor no bairro do Jabaquara. Miriam Sumie Saito coordena um grupo de dezenove alunos, incluindo sete jovens estudantes dos cursos de língua japonesa do templo Emyôji - da comunidade budista Nichiren-sĥे do Brasil, cuja professora é a monge Suzana Tomoko Ishimoto (primeira kotoísta, à esquerda na Fig. 2) - e da Escola Shiinomi, situados nas imediações de sua residência na zona sul.

0 grupo Miwa é liderado pela segunda geração dentro do mesmo núcleo familiar e uma terceira geração já estaria sendo encaminhada. Todos os três filhos do casal Saito aprenderam koto ou shakuhachi, sendo que a caçula, Sílvia Shinobu, foi iniciada no koto pela própria avó e chegou a obter aulas em Quioto, além do aprendizado de taiko e a formação em violino e piano erudito ocidental. Portanto, em síntese, poderíamos afirmar que herança familiar e solidariedade constituem os traços predominantes do grupo.

\section{Associação Brasileira de Música Clássica Japonesa}

A fundação da Associação Brasileira de Música Clássica Japonesa (ABMCJ) foi estimulada por imigrantes do pós-guerra, que aqui chegaram com suas titulações musicais.

A retomada do fluxo imigratório no pós-guerra significou também para a música o que Tomoo Handa analisou em relação às artes plásticas: "a recuperação do senso artístico que dá lustro à vida [...] que os imigrantes perderam na difícil luta pela sobrevivência do período rural" ${ }^{\text {29 }}$. A ABMCJ foi fundada em

29 HANDA, Tomoo. Vida e arte dos japoneses no Brasil. São Paulo: Museu de Arte de São Paulo, Banco América do Sul, 1985. p. 16. 
1982 por líderes das escolas de shakuhachi e sôkyoku da cidade de São Paulo. Os professores da Associação formam o grupo convidado nas comemorações em outros países da América Latina. Desde 1986 o presidente é o "iemoto [literalmente, principal da casa]" - trata-se de um "sistema adotado pela maioria dos gêneros de música e dança artística e está organizado em escolas ou linhagens hierarquicamente estruturadas, com o iemoto na liderança com poderes de decisões sobre estilo de performance, licença de professores etc", conforme Hughes (p. 353) ${ }^{30}$ - da Kinko-ryû, Baikyoku V, pseudônimo artístico de Tsuna Iwami ${ }^{31}$ (Fig. 3), compositor de várias obras editadas - para piano, flauta, canto, violoncelo e shakuhachi com orquestra. Proveniente de Tóquio, ele chegou ao Brasil em 1956, com sua mãe Tomii Iwami, professora e performer da Yamada-rytu.

A partir de então, Baiyoku $V$ tem-se apresentado como intérprete de shakuhachi ao lado das melhores kotoístas, começando com sua mãe e, posteriormente, com Tomoi Inoki, Yûko Ogura, Gakkyo Yumoto e Utahito Kitahara. Organizou também vários recitais em importantes palcos da cidade de São Paulo, tais como o do Museu de Arte e o do Teatro Municipal, irrestritos aos nikkei. Viaja constantemente ao Japão para os encontros da Kinko-rŷu, quando acontecem as cerimônias de outorga de certificados, ou para apresentações, chegando a gravar um especial sobre a história do shakuhachi para a rede televisiva NHK. Em São Paulo, gravou também alguns programas especiais na TV Cultura.

Fato curioso é que a maioria do alunado do professor não possui ascendência nipônica. Entre os oito alunos que figuram nos programas das apresentações, apenas três são nikkei: o imigrante Baiô Natori e os nisei Júlio Baiko Kobayashi e Máximo Hanada. E dos outros cinco alunos, quatro são músicos profissionais, entre os quais ele destaca o etnomusicólogo Dale Bai-Ô Olsen e o regente, educador e musicólogo Danilo Baikyo Tomic (Fig. 3). 0 professor Iwami salienta: "Eles conhecem e valorizam

30 Hughes, David. Japan. In: MYERS, Helen (Ed.). Ethnomusicology: historical and regional studies of East Asia. Nova Iorque; Londres: W.W. Norton, 1993. cap. 2, p. 345-363.

31 Nascido em 1923, iniciou os estudos de shakuhachi aos sete anos de idade. No ano do final da Segunda Guerra conquistou a titulação máxima da Kinkorŷu, com apenas 19 anos de idade, como sucessor direto de Hodô Araki IV. Estudou também okuralo (flauta de metal com sistema de chaves e embocadura de shakuhachi) e composição com Kishio Hirao, discípulo de Vincent D’Indy e César Franck. Formou-se geofísico e químico pela Universidade de Quioto. 
a música artística japonesa mais que os próprios descendentes." E prossegue com um tom incógnito:

No Brasil, duas escolas diferentes como a Tozan-ryû e a Kinkoryû podem tocar juntas, o que não é possível no Japão. [...] No Brasil, a sociedade é mais horizontal, sem muita hierarquia, e no Japão a sociedade é mais verticalizada. E não tem sentido a verticalização no Brasil. ${ }^{32}$

Outro professor atuante nas apresentações da ABMCJ é Shôjirô Shûzan Saeki, da Academia Tozan-rŷu. Imigrante de 1973, o professor Saeki valoriza a relação de companheirismo junto aos alunos, cuja maioria também não é nikkei, afirmando:

A maioria do repertório da Tozan-ryû é polifonia a duas vozes e é preciso fazer música dialogando um shakuhachi com outro. E a cada contato há o desejo de voltar novamente. Música é natureza e ninguém pode forçar a natureza. ${ }^{33}$

As apresentações regulares da Associação são: a abertura da programação "Colônia Geinôsai (p. 127) ${ }^{34}$ [Mostra de música e dança da colônia japonesa]" que, desde 1966, acontece no terceiro ou quarto domingo de junho, mês do aniversário da imigração; e o Concerto Beneficente bienal em prol da Casa Esperança, asilo de excepcionais mantido pela comunidade. Nessa ocasião é possível ouvir Tomoi Inoki, uma exímia intérprete nisei da Yamada-ry $\hat{u}$, ex-aluna de Tomii Iwami. Apesar das raras apresentações conjuntas da ABMCJ, os grupos que a integram, principalmente os de koto, têm uma programação mais constante. E, nesse caso, a Associação funciona como órgão centralizador dos convites que chegam de diversos locais.

32 Depoimento gravado na fita vídeo n. 4, em 24.07.2003, na residência do professor Iwami, no Morumbi, bairro nobre na zona sudoeste.

33 Depoimento gravado em fita áudio n. 10, lado B, no dia 11.02.2001, quando foi realizado o primeiro encontro 2001 dos alunos, na residência do professor Saeki, situada no bairro do Jabaquara.

34 Trata-se da vitrine dos grupos musicais e de dança tradicional, popular e clássica da comunidade nikkei. Poderia ser considerado um continuum do "Engeitaikai [Show de Variedades] que costumava ocorrer no navio da imigração, durante a travessia do Equador" (Cf. HOSOKAWA, Shûhei. História da música entre os nikkei no Brasil: enfocando as melodias japonesas. In: ENCONTRO NACIONAL DE PROFESSORES UNIVERSITÁRIOS DE LÍNGUA, LITERATURA E CULTURA JAPONESA, 4., 1993, São Paulo. Anais... São Paulo: Centro de Estudos Japoneses da USP, 1993. p. 125-48. 
As escolas Ikuta-ryû apresentam uma intensa atividade tanto no ensino como na performance. Desde a sua fundação, em 1982, mais de noventa alunos freqüentaram a Miyagi- $k a i^{35}$ do Brasil, liderados pelas professoras Yûko Ogura e Reiko Nagase (Fig. 4). Atualmente conta com vinte e sete participantes, cuja metade ainda é issei. Na ocasião do centenário do tratado de amizade Brasil-Japão, em 1995, o grupo empenhou-se em trazer trinta professores do Japão, que se apresentaram em São Paulo, Rio de Janeiro e Brasília. A professora Ogura, iniciada pela sua mãe Kikue Hayashida - "pioneira no ensino do estilo Yamada no Brasil” (p. 121) - $^{36}$, estudou diretamente com o compositor Michio Miyagi, em Tóquio, entre 1953-56.

Nascida em Promissão (município a oeste do estado de São Paulo), a professora Yûko reside desde a infância no bairro de Pinheiros, região oeste, onde ainda são ministradas as aulas do Miyagi-kai. Uma vez por semana ela se desloca para a Associação da Província de Mie, na Vila Mariana, região meridional da cidade, onde atende a três alunas. Eventualmente, vai até Belém do Pará, onde seis pessoas se dedicam ao treinamento de koto.

Reiko Nagase imigrou no ano de 1969 e ensina o koto para suas duas filhas e uma amiga (que imigrou no mesmo ano), durante as poucas horas de folga que restam do trabalho em sua agência de viagens. A professora Nagase, proveniente de Kumamoto e casada com nisei brasileiro, iniciou o aprendizado do instrumento no Japão e aqui foi aluna, durante sete anos, de Masae Tani, a principal articuladora do Miyagi-kai brasileiro.

o Grupo Seiha Brasil de Koto (GSBK) é a escola mais jovial, considerando-se a faixa etária dos alunos e professores, o repertório e as atitudes de interação social. 0 grupo foi fundado por Kiyoko Gakkyo Yûmoto, em 1982, mas, devido ao fato da fundadora ter residido apenas cinco nos no Brasil, a liderança foi logo repassada para a atual professora, Tamie Utahito Kitahara (fig. 5), que ministra algumas aulas na sua residência, no $\mathrm{Bu}-$ tantã, e reúne um grupo de jovens no bairro vizinho, chamado Rio Pequeno. Além disso, munida de koto, sangen, partituras e celular, Tamie atravessa a cidade desde o extremo noroeste, onde mora, até Santo André - município a sudeste, onde morou logo que imigrou aos doze anos de idade - ou até a Vila Mariana, no

35 Subescola da corrente Ikuta, fundada pelo compositor Michio Miyagi (18941956), que introduziu o koto baixo de dezessete cordas e modernizou o repertório, aproximando-o das possibilidades sonoras ocidentais.

36 Cf. OLSEN, Dale. Japanese music in Brazil. Journal of the Society for Asian Music, Austin, v. 14, n. 1, p. 111-31, 1982. 
Centro de Minyô, e, às vezes, leciona em domicílio. Poupando tempo e desconforto das alunas, a professora Tamie Utahito Kitahara prefere expor-se aos riscos em uma atitude missionária, conforme podemos constatar neste seu depoimento:

Sabe, em São Paulo, as distâncias, o trânsito, o perigo de sair de casa... Então, se eu não resolvesse ir até a casa dos alunos, provavelmente eles não estariam aprendendo koto. Ensinar, para mim, é como uma missão aqui na Terra. ${ }^{37}$

Em vinte e um anos de GSBK, foram realizadas quinze audições envolvendo em torno de sessenta pessoas, sendo a maioria das alunas sansei. Ademais do perfil jovial do grupo, há muitas relações de parentesco entre as integrantes. Na fig. 5 vemos a professora, à esquerda, sua filha e as outras duas são primas entre si. No grupo Seiha há um trio sankyoku exclusivamente feminino, formado pela professora, por Mari Saito e Kitty Pereira. Trata-se de uma raridade, pois a jovem Mari Saito - aluna exemplar em japonês e minyô, além do koto - toca shakuhachi, sendo a única mulher das escolas Tozan e Kinko. 0 grupo Seiha é o que mais interage com artistas profissionais da maioria paulistana, dispondo-se a relacionar-se com outros mundos musicais. A professora, por exemplo, já participou em gravação do primeiro CD do grupo Mawaca, de música "étnica" ${ }^{\text {"38 }}$, e em projetos didáticos como os de Tereza Alencar ${ }^{39}$ e de Paulo Tatit ${ }^{40}$.

\section{Considerações finais}

0 trabalho enfatizou a questão da resistência cultural, característica do imigrante, pois este é o verdadeiro agente enculturador, já que se trata de música tradicional. Na atribuição do significado que o fazer musical desempenha para os co-autores da pesquisa, confirmou-se o pressuposto de que a etnici-

37 Entrevista anotada na caderneta de campo, p. 29, em 09.02.2001, na residência da aluna veterana Misako Fukushima, no bairro da Saúde.

38 PUCCI, Magda. Mawaca. São Paulo: MCD, 1998. (CD MCD013).

39 ALENCAR, Tereza. Canto de vários cantos. São Paulo: Teca Oficina de Música, 1999. 1 CD. (Registro em CD de resultado didático).

40 TATIT, Paulo; Sandra Perez. O som é assim: instrumentos orientais. São Paulo: SESC, TV Cultura, 2002. (Projeto teatral e televisivo). 
dade é mais acentuada no grupo de Okinawa, pela ausência de nikkei de Naichi e, principalmente, de outras ascendências. No entanto, a delimitação Okinawa/Naichi é a mais contundente, conforme pudemos confirmar esse acentuado sentimento de pertença nas palavras dos líderes dos grupos da Difusão da AOB, moradores da Vila Alpina, zona leste de São Paulo. Segundo Kensho Tengan: "Para nós, o koten não é canto de samurai"41; e Ryoko Kuniyoshi complementa: "As cordas do koto de Naichi soam mais estridentes e o toque é mais agressivo. 0 nosso toque é mais suave e delicado" 42 .

A herança familiar é mais acentuada no grupo Miwa que encaminha a terceira geração de descendentes do casal Miyoshi. E a ideologia, entendida como um reflexo da realidade moderna e ocidentalizada, prevalece na ABMCJ. No entanto, cada uma dessas atitudes - etnicidade, ideologia e herança cultural - não deve ser considerada tão estanque. Os grupos mantêm a conduta dos fundadores, constituindo mais um patamar de etnicidade entre os seguidores da mentalidade pré-guerra e os do pós-guerra. 0 traço da herança familiar não foi observado no grupo de Okinawa, mas é comum às filhas de todas as professoras da Ikuta-ryû e Yamadaryû. A etnicidade só não procede nos descendentes caucasianos. 0 eixo comum é a manutenção por ideologia incutida pela educação familiar, pelo meio social ou pela mídia.

Essas atitudes culturais podem ser consideradas tanto como manutenção de valores da terra emigrada, quanto como adaptação aos valores da terra de acolhimento. Adotando a equiparação do ato de emigrar com o luto, de Francisco Hashimoto ${ }^{43}$, o fazer musical para os issei seria um eficaz meio de "gerenciar o luto da terra amada”, trazendo com nitidez a presença do objeto amado ausente. Kazuyo Kuze, aluna do Miyagi-kai e educadora aposentada, acrescenta: "0 koto prepara o aprendiz para enfrentar as perdas e feridas da vida, para construir a firmeza do caráter, a sensibilidade e a verdadeira alma japonesa [...]"44. Além de

41 Entrevista gravada na fita áudio n. 26, lado A, em 29.01.1997, na sede central da AOB.

42 Em conversa por telefone, anotada na caderneta de campo, p. 60, em 18.12.2003.

43 Cf. HASHIMOTO, Francisco. Sol nascente no Brasil: cultura e mentalidade. Assis, SP: HVF Arte \& Cultura, 1995. p. 31.

44 Entrevista oral anotada no questionário semi-estruturado respondido em 10.02.2003, na Associação Mie-ken. Órfã de guerra, ela veio para o Brasil ensinar no ensino médio da escola regular, mantida pelo governo japonês, em São Paulo. 
confirmar o valor terapêutico, ela sugere que a arte japonesa se confunde com modos de ser embutidos nos preceitos budistas, aproximando-se de uma assertiva intrigante do professor Hans Koellreutter: "No Japão não há ética. Tudo é estética."

Reunindo a análise de Hashimoto e o papel da religião para o imigrante, apontado por Roger Bastide ${ }^{46}$, a música seria uma forma de "cultivar o jardim secreto do país abandonado" e reconstruir o objeto amado. E esta reconstrução deve ser a mais pura possível, já que se encontra deteriorada, ou comercializada, no Japão moderno. 0 professor Shûzan Saeki denuncia a origem da impureza vinda do Ocidente:

Na música Gagaku, o koto era afinado pela quinta natural, onde o coração fica mais puro. Com a introdução do piano, a música tornou-se comercial, o homem perdeu sua profundidade, aumentando a ganância e a propensão para guerrear. ${ }^{47}$

E os descendentes internos ou externos à comunidade, na busca de um refinamento pessoal, de suavizar suas vidas, ou de aperfeiçoamento espiritual, reconstroem um mundo idealizado, livre de contaminações. Segundo a Sra. Kinoshita, nisei, mãe de uma aluna do Miwa-kai:

Aprender koto ajuda a criança a fixar o idioma, entrando em contato com suas raízes de maneira prazerosa. E também, como a juventude de hoje corre muitos riscos, ela fica ocupada, prevenindo as possibilidades de más companhias, vícios, enfim, de fazer tudo que não presta. ${ }^{48}$

Conforme Márcio Valério, um aluno de ascendência caucasiana do professor Saeki:

Para mim, música é a principal forma de entrar em contato comigo mesmo, ou aspectos do meu interior, para atingir outros

45 Depoimento anotado em aula particular ministrada para um grupo de alunos de composição da Unicamp, em 1980, em minha residência, em São Paulo.

46 Bastide, Roger. Brasil, terra de contrastes. Tradução de M. Isaura Queiroz. 4. ed. São Paulo: Difusão Européia do Livro, 1971. p. 193.

47 Depoimento gravado em fita cassete áudio n. 11, lado B, no dia 13.02.2001, na residência do professor Saeki.

48 Em conversa informal anotada na caderneta de campo p. 58, em 09.02.2003, no primeiro encontro 2003 do Miwa-kai, no sítio do casal Saito, em São Bernardo do Campo. 
níveis de consciência. Contribui para a minha elevação espiritual, serena a mente e purifica o coração. ${ }^{49}$

Ou ainda, segundo uma aluna nisei da professora Ogura, Clarice Ikeda:

Quando ouço é a emoção de alguém que entendo.

Quando canto é a minha emoção que estou externando.

Música é alegria, é vida, é arte, é cultura, é terapia. ${ }^{50}$

Para finalizar, na tentativa de traçar um perfil genérico, sem pretensões de definir um comportamento padrão, poderíamos sumarizar que: para ambos, imigrante e descendente, interno ou externo à comunidade, a música "alternativizada" (ver p. 127) representaria a reconstrução da terra ou de uma terra perdida no espaço e no tempo.

49 Questionário semi-estruturado respondido e enviado pela Internet, em 21.07.2003.

50 Questionário semi-estruturado respondido e enviado pela Internet, em 20.07.2003. 
Figura 1: Grupos de koten da AOB na sede do Centro Cultural Okinawa do Brasil, em Diadema. Foto Alice Lumi Satomi.

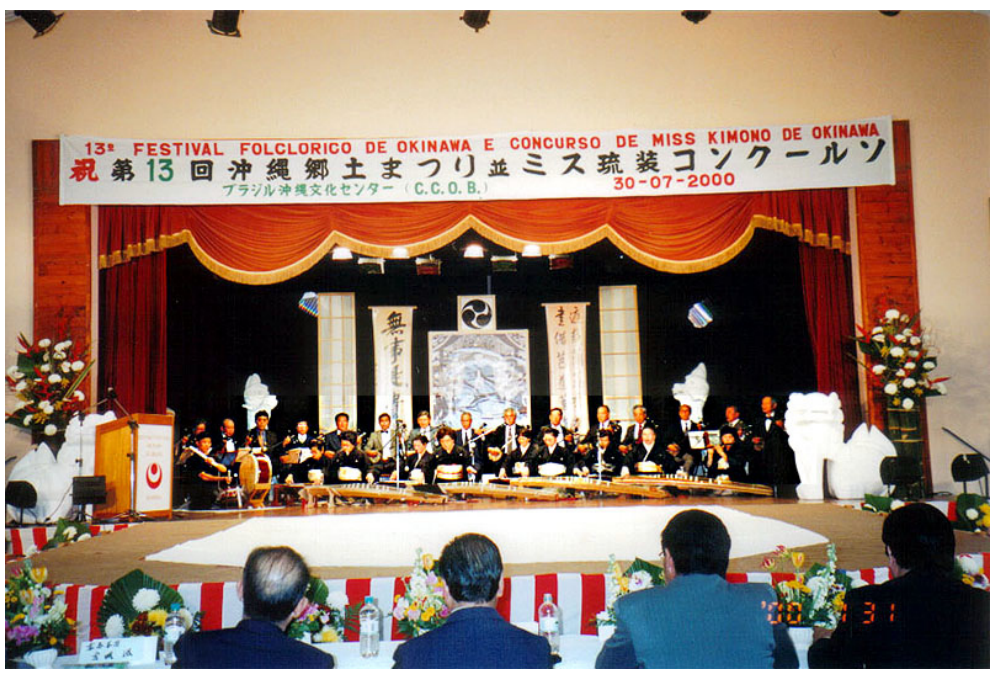


Figura 2: Grupo Miwa na cerimônia de abertura da Homenagem póstuma aos Imigrantes, no auditório da SBCJ, em 18.06.2003. Foto Alice Lumi Satomi.

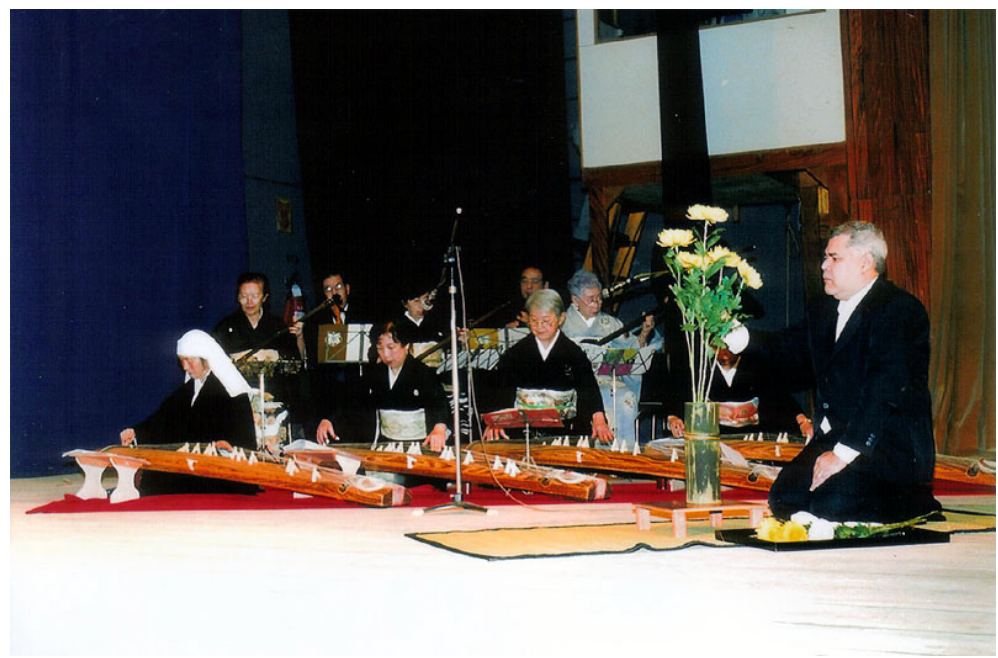

Figura 3: Baikyo Tomic e Iwami Baikyoku V, da Kinko-ryû, no SESC Vila Mariana, em 24.01.2001. Foto Alice Lumi Satomi.

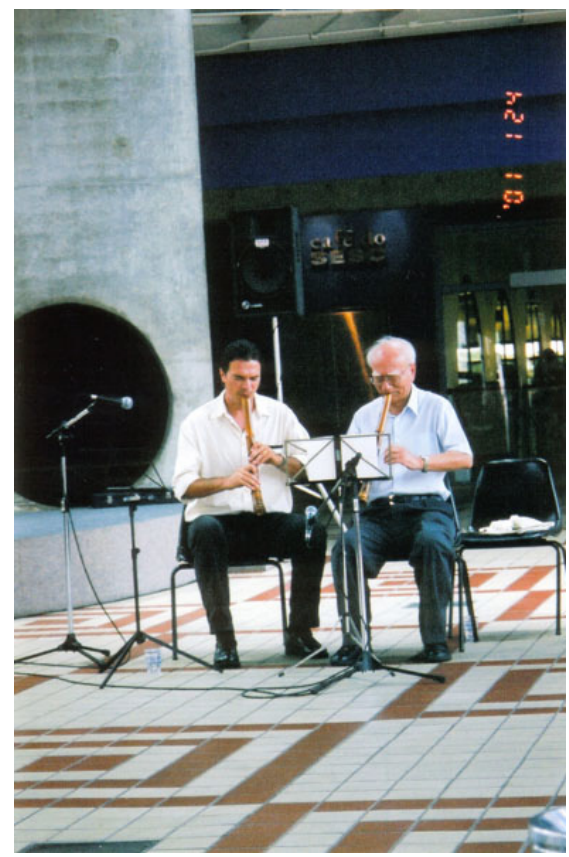


Figura 4: Yûko Ogura, Reiko Nagase e Nobue Sugio, do Grupo Miyagi, no SESC, em 24.01.2001. Foto Alice Lumi Satomi.

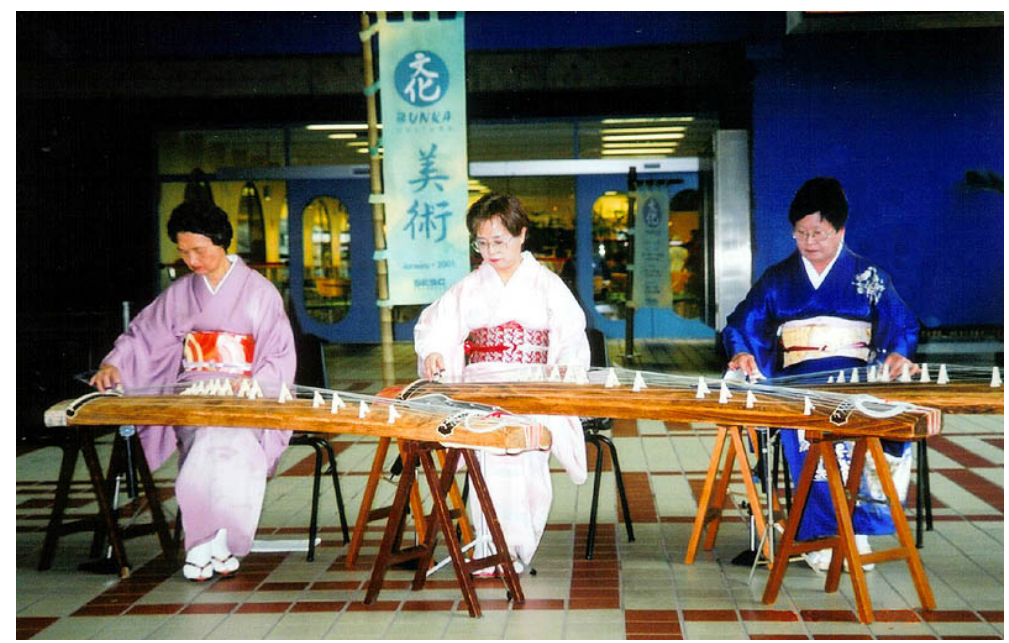

Figura 5: Shûzan Saeki, Utahito Kitahara e alunas do GSBK, no SESC, em 27.01.2001. Foto Alice Lumi Satomi.

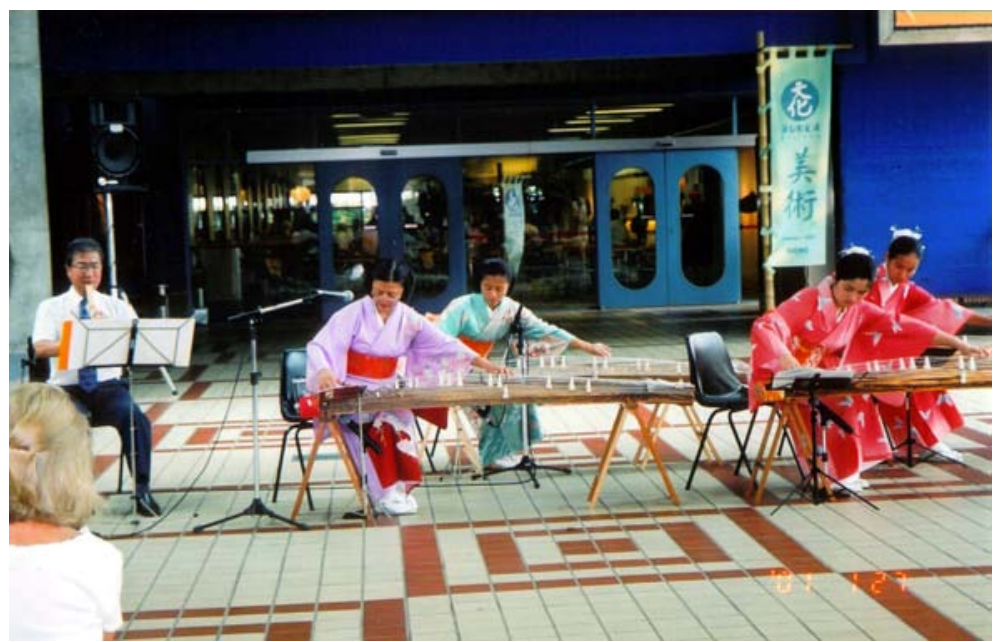

